\title{
Stagnation Point Flow of EMHD Micropolar Nanofluid with Mixed Convection and Slip Boundary
}

\author{
Shahzada Muhammad Atif, ${ }^{1}$ Muhammad Abbas $\left(\mathbb{D},{ }^{2}\right.$ Umair Rashid, ${ }^{3}$ \\ and Homan Emadifar $\mathbb{D}^{4}$ \\ ${ }^{1}$ Department of Mathematics, Capital University of Science and Technology, Islamabad, Pakistan \\ ${ }^{2}$ Department of Mathematics, University of Sargodha, Sargodha 40100, Pakistan \\ ${ }^{3}$ CAS Key Laboratory of Mechanical Behavior and Design of Materials, Department of Modern Mechanics, \\ University of Science and Technology of China, Hefei 230026, Anhui, China \\ ${ }^{4}$ Department of Mathematics, Islamic Azad University, Hamedan Branch, Hamedan, Iran
}

Correspondence should be addressed to Muhammad Abbas; muhammad.abbas@uos.edu.pk and Homan Emadifar; homan_emadi@yahoo.com

Received 10 April 2021; Revised 27 May 2021; Accepted 19 June 2021; Published 2 July 2021

Academic Editor: Muhammad Imran Asjad

Copyright (C) 2021 Shahzada Muhammad Atif et al. This is an open access article distributed under the Creative Commons Attribution License, which permits unrestricted use, distribution, and reproduction in any medium, provided the original work is properly cited.

\begin{abstract}
The aim of this numerical research is to study the stagnation point flow of the electrical magnetohydrodynamic micropolar nanofluid with slip conditions past a stretching sheet. The phenomenon of linear thermal radiation, Ohmic and internal heating, has also been considered in the energy equation. The modelled PDEs are converted into ODEs via similarity transformation, and converted ODEs are tackled via the shooting technique. The features of assorted parameters on the axial and angular velocities and energy and concentration fields are sketched. The numerical values of the Sherwood and Nusselt numbers have been computed numerically and displayed in the form of tables. Our analysis shows that the heat transfer rate is decreased as the thermal slip parameter and the diffusion slip parameter are enhanced. The present study illustrates that the energy and concentration distribution are decreased with each of the mass free convection parameter, stagnation parameter, and thermal free convection parameter.
\end{abstract}

\section{Introduction}

The phenomenon of transfer of heat, which has significant application in many engineering and industry disciplines, is affected positively by the implementation of an appropriate magnetic field. The investigation of magnetohydrodynamic flow past a heated surface has gained significant attention due to its vast applications in engineering problems, i.e., magnetohydrodynamic power generators, petroleum industries, and crystal growth. Swedish scientist Alfven [1] was the first to introduce the magnetohydrodynamic fluid flow. He won the Nobel Prize in Physics for his work on MHD in 1970. He described the class of magnetohydrodynamic waves, which are now known as Alfven waves. Zheng et al. [2] reported the magnetohydrodynamic 2-D (dimensional) flow past a porous shrinking surface with slip conditions with conclusion that an acclivity in the shrinking parameter enhances the thermal boundary layer. By considering the slip effects in a porous medium, Ullah et al. [3] explored the magnetohydrodynamic (MHD) Casson fluid and noticed that boosting the unsteadiness parameter enhances the wall shear stress. Rahbari et al. [4] examined the magnetohydrodynamic Maxwell fluid flowing through parallel plates and determined that increase in the Deborah number increases the velocity. By investigating heat transfer in the magnetohydrodynamic flow past a radially shrinking/ stretching sheet, Soid et al. [5] concluded that dual solutions exist only in case of suction and for small values of magnetic parameters. Decline in surface drag due to increment in the squeezed flow parameter in Carreau fluid with thermal radiation and magnetohydrodynamic effect past a sensor surface was reported by Atif et al. [6]. Transverse 
magnetohydrodynamic effect on nonlinear stretching sheet was ascertained by Ramana et al. [7]. They used modified Fourier flux law and concluded that the relaxation and retardation time have opposite effects on the thermal profile. For further studies, see $[8,9]$.

Stagnation point flow is one of the fields in which scientists and engineers show keen interest. Some of the recent studies include the following: For MHD viscoelastic nanofluid, the dual solution of stagnation point past a porous stretching surface with radiation effect was reported by Juosh [10]. It was found that an acclivity in the Deborah number contributes to upsurge in the drag coefficient. Impact of MHD on stagnation point flow of a nanofluid with nonuniform thermal reservoir was analyzed by Rashid et al. [11]. Pal [12] put light on magnetohydrodynamic stagnation point flow with suction effect and reported that the Sherwood number was decreased as the Lewis number increased. Bioconvective stagnation point of Maxwell nanofluid flow past a convectively heated surface was reported by Abbasi et al. [13]. They observed that energy, concentration, and density profiles were higher for nonconvective surfaces than in convective heated surfaces. Lund et al. [14] performed the stability analysis and reported the dual solution of MHD stagnation point of Casson fluid. Their main observation was that the sign of the smallest eigenvalues shows that the first solution was stable. Effect of solar radiation on MHD stagnation point nanofluid flow was discussed by Ghasemia and Hatami [15] with a key finding that the energy profile is hiked as the Biot number is increased rapidly. The phenomena of thermal radiation have much significance in the transfer of heat and were discussed by many authors in the literature [16-19].

Micropolar fluids can be characterized as fluids which exhibit the micro-rotational effects and micro-rotational inertia. Analysis of the micropolar fluids has been an active field of interest for many researchers. This class of fluids possesses certain simplicity and elegance in their mathematical formulation which should appeal to mathematicians. The micropolar fluids can support couple stress and body couples only. Physically, they may represent adequately the fluids consisting of dipole elements. Certain anisotropic fluids e.g., liquid crystals which are made up of dumbbell molecules are of this type. In fact, animal blood happens to fall in this category. Other polymeric fluids and fluids containing minute amounts of additives may be represented by the mathematical model underlying micropolar fluids. Eringen [20,21], through his pioneering work, invited the attention of the researchers' community in this interesting area of fluid dynamics. Sui et al. [22] investigated the nonlinear constitutive diffusion model in the micropolar fluid with the main finding that both the velocity and energy profiles are increased as the power exponent $n$ is decreased from 1 . Heat transfer of the free convective micropolar fluid with heat source past a shrinking sheet was noticed by Mishra et al. [23]. They observed that the fluid motion is declined as the heat generation coefficient is upsurged. Atif et al. [24] analyzed the bioconvective magnetohydrodynamic micropolar nanofluid with stratification and reported that the density distribution decreases as the density stratification and mixed number parameter are hiked.
Micropolar nanofluid flow with nonlinear convection and multiple slip effects was examined by Zemedu and Ibrahim [25] with concluding remarks that boosting the solutal nonlinear convection parameter causes an increase in the velocity.

The heat transfer in base fluids like mineral oils, water, and ethylene glycol is not as much effective as in nanofluids [26-31]. Nanofluids have the ability to improve the heat transfer properties. Their ability to move through capillaries and microchannels without making any blockage in flow makes them unique. By considering the induced magnetic field, Atif et al. [32] investigated the magnetohydrodynamic micropolar Carreau nanofluid and found that the angular velocity is increased rapidly as the magnetic Prandtl number increases. Three-dimensional Eyring-Powell nanofluid with Arrhenius energy was reported by Taseer et al. [33]. Khan [34] reported that nanoparticle dispersion reduces the Nusselt number in a partially heated vertical annulus. For a solutal-dominated regime, both Nusselt and Sherwood numbers declined for micropolar nanofluid as reported by Manaa et al. [35].

In recent years, researchers have paid serious attention to electrical magnetohydrodynamics. Electrical magnetohydrodynamic stagnation point nanofluid with mixed convection and slip boundary over a stretching surface was scrutinized by Hsiao [36]. A major conclusion was that an acclivity in either the electrical or the magnetic parameter led to an upsurge in the temperature profile. Literature review indicates that the EMHD stagnation point micropolar nanofluid with mixed convection and slip boundary has not been investigated yet. In the present article, linear thermal radiation, Joule's heating, and heat source have also been incorporated in the energy equation. In this study, four aspects have been focused. First, the heat and mass transfer of micropolar nanofluid are addressed. Second, the impact of thermal radiation and electrical magnetohydrodynamics on different profiles is examined. Third, the stagnation point flow is analyzed. Fourth, the analysis of the mixed convection and slip boundary conditions is performed. The arising ordinary differential equations for the problem are tackled through the shooting method. The influence of all the prominent parameters is examined numerically and displayed graphically.

\section{Mathematical Model}

An incompressible, 2D, mixed convection micropolar nanofluid flow over a stretching sheet with slip effects has been analyzed. By using Ohm's law and Maxwell's equations, the continuity equation, linear and angular momentum, and fluid energy and concentration equations have been formulated. Joule's heating, thermal radiation, and heat source effects have also been considered in the energy equation. $C, C_{\infty}, T$, and $T_{\infty}$ denotes the surface concentration, ambient concentration surface temperature, and ambient temperature, respectively. The flow is assumed along the $x$ - axis which is considered to be in the upward direction, whereas the $y$ - axis is perpendicular to the sheet. A uniform magnetic field $B_{0}$ has been implemented towards 
the $y$-axis as illustrated in Figure 1. It is also assumed that the magnetic Reynolds number is very small due to which induced magnetic number is ignored.
In the light of the above assumption, the governing equations of the modelled problem are as follows [36, 37]:

$$
\begin{aligned}
\frac{\partial u}{\partial x}+\frac{\partial v}{\partial y}= & 0 \\
u \frac{\partial u}{\partial x}+v \frac{\partial u}{\partial y}= & U_{\infty} \frac{\partial U_{\infty}}{\partial x}+\left(v+\frac{k}{\rho}\right) \frac{\partial^{2} u}{\partial y^{2}}+\frac{k}{\rho_{f}} \frac{\partial N}{\partial y}+\frac{1}{\rho} \sigma B_{0}^{2}(U-u) \\
& +g_{x} \beta_{t}\left(T-T_{\infty}\right)+g_{x} \beta_{c}\left(C-C_{\infty}\right)+\frac{1}{\rho} \sigma E_{0} B_{0}, \\
u \frac{\partial N}{\partial x}+v \frac{\partial N}{\partial y}= & \frac{\gamma}{(\rho j)}\left(\frac{\partial^{2} N}{\partial y^{2}}\right)-\frac{k}{(\rho j)}\left(2 N+\frac{\partial u}{\partial y}\right), \\
u \frac{\partial T}{\partial x}+v \frac{\partial T}{\partial y}= & \alpha \frac{\partial^{2} T}{\partial y^{2}}-\frac{1}{\left(\rho C_{p}\right)} \frac{\partial q_{r}}{\partial y}+\frac{\sigma\left(u B_{0}-E_{0}\right)^{2}}{\left(\rho C_{p}\right)}+\tau\left[D_{B} \frac{\partial C}{\partial y} \frac{\partial T}{\partial y}+\frac{D_{T}}{T_{\infty}}\left(\frac{\partial T}{\partial y}\right)^{2}\right] \\
& +\frac{Q_{0}}{\left(\rho C_{p}\right)}\left(T-T_{\infty}\right), \\
u \frac{\partial C}{\partial x}+v \frac{\partial C}{\partial y}= & D D_{B} \frac{\partial^{2} C}{\partial y^{2}}+\frac{D_{T}}{T_{\infty}} \frac{\partial^{2} T}{\partial y^{2}} .
\end{aligned}
$$

The related $\mathrm{BCs}$ are as follows:

$$
\left.\begin{array}{l}
u_{w}-c x=L \frac{\partial u}{\partial y}, \\
v=v_{w}=a x, \\
N=0, \\
T=T_{w}+k_{1} \frac{\partial T}{\partial y}, \\
C=C_{w}+k_{2} \frac{\partial C}{\partial y},
\end{array}\right\} \text { at } y=0,
$$

In equation (3), the Rosseland radiative heat flux $q_{r}$ is given by $q_{r}=-\left(4 \sigma^{*} / 3 \kappa^{*}\right)\left(\partial T^{4} / \partial y\right)$. The spin gradient viscosity is given by $\gamma=(\mu+(k / 2)) j$, where $j=\nu / a$ and $k$ represents the microinertia density and vortex viscosity, respectively. For nondimensionlization, the following transformation [36] has been considered:

$$
\begin{aligned}
& \psi=x \sqrt{a v} f(\eta), \\
& N=a x \sqrt{\frac{a}{v}} g(\eta), \\
& \eta=y \sqrt{\frac{a}{v}} \\
& \theta(\eta)=\frac{T-T_{\infty}}{T_{w}-T_{\infty}}, \\
& T=T_{\infty}+A x \theta(\eta) \\
& \phi(\eta)=\frac{C-C_{\infty}}{C_{w}-C_{\infty}}, \\
& C=C_{\infty}+B x \phi(\eta) .
\end{aligned}
$$

Continuity equation (1) is satisfied automatically, and equations (2)-(5) yield the following: 


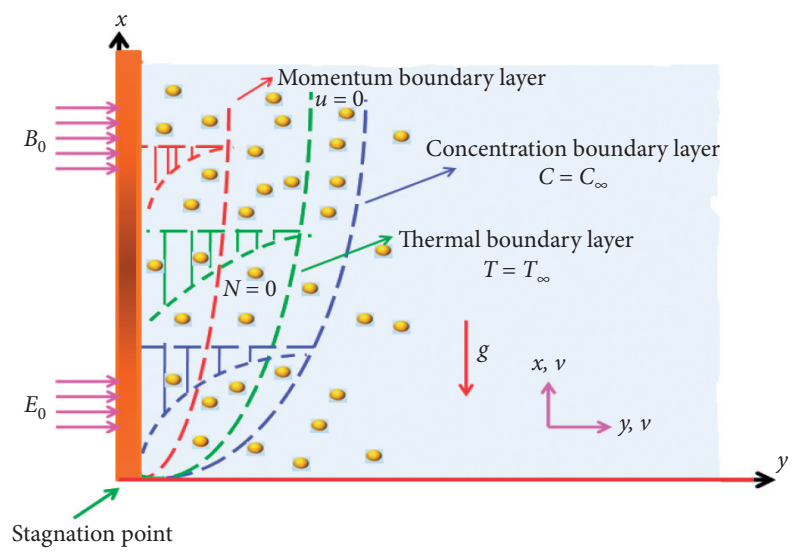

FIgURE 1: Flow configuration.

$$
\begin{gathered}
(1+K) f^{\prime \prime \prime}-f^{\prime 2}+f f^{\prime \prime}+K g^{\prime}+S_{0} \\
-M\left(f^{\prime}-1-E\right)+G_{t} \theta+G_{c} \phi=0 \\
\left(1+\frac{K}{2}\right) g^{\prime \prime}-g f^{\prime}+f g^{\prime}-K\left(2 g+f^{\prime \prime}\right)=0 \\
\left(1+\frac{4}{3} R d\right) \theta^{\prime \prime}+\operatorname{Pr}\left[f \theta^{\prime}+\lambda \theta+N b \theta^{\prime} \phi^{\prime}+N t \theta^{\prime 2}\right. \\
\left.+M E c\left(f^{\prime 2}+E^{2}-2 E f^{\prime}\right)\right]=0 \\
\phi^{\prime \prime}+\operatorname{Sc} f \phi^{\prime}+\frac{N t}{N b} \theta^{\prime \prime}=0 .
\end{gathered}
$$

The associated boundary conditions in the dimensionless form are as follows:

$$
\left.\begin{array}{l}
\begin{array}{l}
f=S, \\
f^{\prime}=1+\delta_{1} f^{\prime \prime},
\end{array} \quad \text { at } \eta=0, \\
\begin{array}{l}
g=0, \\
\theta=1+\delta_{2} \theta^{\prime},
\end{array} \\
\phi=1+\delta_{3} \phi^{\prime} \\
f^{\prime} \longrightarrow 0, \\
\begin{array}{l}
\longrightarrow \\
\theta \longrightarrow 0,
\end{array} \\
\phi \longrightarrow 0,
\end{array}\right\} .
$$

Here, $\operatorname{Pr}=v / \alpha$ denotes the Prandtl number, $S_{0}=U_{\infty}^{2}\left(c+L f^{\prime \prime}(0) \sqrt{a^{3} / v}\right)^{2} / a^{2} u_{w}^{2}$ represents the stagnation parameter, $\mathrm{Ec}=a^{2} x^{2} / C_{p}\left(T_{w}-T_{\infty}\right)$ denotes the Eckert number, $\mathrm{Nb}=\tau D_{B}\left(C_{w}-C_{\infty}\right) / \nu$ denotes the Brownian motion parameter, $K=k / \mu$ represents the micropolar parameter, $\quad G_{t}=g_{x} \beta_{t}\left(T_{w}-T_{\infty}\right)\left(c+L f^{\prime \prime}(0) \sqrt{a^{3} / \nu}\right) / a^{2} U_{w}$ represents the thermal free convection parameter, $M=\sigma B_{0}^{2} / a \rho$ represents the magnetic number, $E=E_{0} / B_{0} U$ represents the electric field parameter, $\mathrm{Nt}=\tau D_{T}$
$\left(T_{w}-T_{\infty}\right) / \nu T_{\infty}$ denotes the thermophoresis parameter, $S=$ $(c / a)+(L / a) f^{\prime \prime}(0) \sqrt{a^{3} / v}$ denotes the slip parameter, Sc $=$ $\nu / D_{B}$ denotes the Schmidt number, $G_{c}=g_{x} \beta_{c}\left(C_{w}-C_{\infty}\right)\left(c+L f^{\prime \prime}(0) \sqrt{a^{3} / v}\right) / a^{2} U_{w}$ denotes the mass free convection parameter, $\mathrm{Rd}=4 \sigma^{*} T_{\infty}^{3} / k \kappa^{*}$ denotes the thermal radiation parameter, $\lambda=Q_{0} / a\left(\rho C_{p}\right)$ denotes the heat generation coefficient, $\delta_{1}=L \sqrt{a / v}$ represents the shear stress parameter, $\delta_{2}=k_{1} \sqrt{a / v}$ represents the temperature slip parameter, and $\delta_{3}=k_{2} \sqrt{a / \nu}$ represents the diffusion slip parameter, where $k_{1}$ and $k_{2}$ are the slip parameters associated with the reference temperature and concentration, respectively.

\section{Quantities of Interest}

The dimensionless Nusselt and dimensionless Sherwood numbers are the most concerning quantities in engineering and industries.

$$
\begin{aligned}
& \mathrm{Nu}=\frac{x q_{w}}{k\left(T_{w}-T_{\infty}\right)}, \\
& \mathrm{Sh}=\frac{x j_{w}}{D_{B}\left(C_{w}-C_{\infty}\right)} .
\end{aligned}
$$

In the nondimensional form, Nusselt and Sherwood numbers are given by

$$
\begin{aligned}
& \mathrm{Nu}_{x} \operatorname{Re}_{x}^{-(1 / 2)}=-\left(1+\frac{4}{3} \mathrm{Rd}\right) \theta^{\prime}(0), \\
& \operatorname{Sh}_{x} \operatorname{Re}_{x}^{-(1 / 2)}=-\phi^{\prime}(0),
\end{aligned}
$$

where $\operatorname{Re}_{x}=a x^{2} / \nu$.

\section{Solution Methodology}

The system of ODEs (8)-(11) along with BCs (12) is tackled numerically by the shooting technique. Now, we introduce $\varsigma_{1}=f, \varsigma_{2}=f^{\prime}, \varsigma_{3}=f^{\prime \prime}, \varsigma_{4}=g, \varsigma_{5}=g^{\prime}, \varsigma_{6}=\theta, \varsigma_{7}=\theta^{\prime}$, $\varsigma_{8}=\phi$, and $\varsigma_{9}=\phi^{\prime}$ as follows: 


$$
\begin{aligned}
& \varsigma_{1}^{\prime}=\varsigma_{2}, \\
& \varsigma_{2}^{\prime}=\varsigma_{3}, \\
& \varsigma_{3}^{\prime}=\frac{1}{1+K}\left[\varsigma_{2}^{2}-\varsigma_{1} \varsigma_{3}-S_{0}-K \varsigma_{5}+M\left(\varsigma_{2}-1-E\right)-G_{t} \varsigma_{6}-G_{c} \varsigma_{8}\right], \\
& \varsigma_{4}^{\prime}=\varsigma_{5}, \\
& \varsigma_{5}^{\prime}=\frac{2}{2+K}\left[\varsigma_{2} \varsigma_{4}-\varsigma_{1} \varsigma_{5}+K\left(2 \varsigma_{4}+\varsigma_{3}\right)\right], \\
& \varsigma_{6}^{\prime}=\varsigma_{7}, \\
& \varsigma_{7}^{\prime}=-\frac{3 \operatorname{Pr}}{3+4 \mathrm{Rd}}\left[\varsigma_{1} \varsigma_{7}+\lambda \varsigma_{6}+M E c\left(\varsigma_{2}^{2}+E^{2}-2 E \varsigma_{2}\right)+\mathrm{Nb} \varsigma_{7} \varsigma_{9}+\mathrm{Nt} \varsigma_{7}^{2}\right], \\
& \varsigma_{8}^{\prime}=\varsigma_{9}, \\
& \varsigma_{9}^{\prime}=-S c \varsigma_{1} \varsigma_{9}-\frac{\mathrm{Nt}}{\mathrm{Nb}} \varsigma_{7}^{\prime} .
\end{aligned}
$$

The corresponding boundary conditions are

$$
\begin{array}{ll}
\varsigma_{1}=S, & \\
\varsigma_{2}=1+\delta_{1} \varsigma_{3}, & \\
\varsigma_{4}=0, & \text { at } \eta=0, \\
\varsigma_{6}=1+\delta_{2} \varsigma_{7}, & \\
\varsigma_{8}=1+\delta_{3} \varsigma_{9} & \\
\varsigma_{2} \longrightarrow 0, & \\
\varsigma_{4} \longrightarrow 0, & \text { as } \eta \longrightarrow \\
\varsigma_{6} \longrightarrow 0, & \\
\varsigma_{8} \longrightarrow 0 &
\end{array}
$$

4.1. Code Validation. For the verification of the correctness of the code, the results of the Nusselt and Sherwood numbers which were presented by Khan and Pop [38] and Hsiao [36] are successfully reproduced. Our simulations have a satisfactory agreement with the already published results of Khan and Pop [38] and Hsiao [36] in the literature which can be seen in Table 1.

\section{Results and Discussion}

Table 2 is displayed to view the effect of the sundry parameters on the dimensionless Nusselt number and Sherwood number. It is observed that a boost in each of the electric parameter $E$, slip parameter $S$, micropolar parameter $K$, thermal radiation parameter $\mathrm{Rd}$, the stagnation parameter $S_{0}$, thermal free convection parameter $G_{t}$, diffusion slip parameter $\delta_{3}$, and mass free convection parameter $G_{c}$, causes an increase in Nusselt number, whereas it decreases for a boost in each of the heat generation coefficient $\lambda$, shear stress parameter $\delta_{1}$, magnetic parameter $M$, and the thermal slip parameter $\delta_{2}$. The Sherwood number is hiked as each of the material parameter $K$, magnetic parameter $M$, thermal free convection parameter $G_{t}$, velocity slip parameter $S$, electric parameter $E, b$ mass free convection parameter $G_{c}$, stagnation parameter $S_{0}$, and heat generation coefficient $\lambda$, and thermal radiation parameter $\mathrm{Rd}$ is boosted. However, it diminishes as the diffusion slip parameter $\delta_{3}$, thermal slip parameter $\delta_{2}$, and shear stress parameter $\delta_{1}$ are increased.

Figures 2-14 are sketched to study the variations occurring due to dimensionless parameters in temperature distribution $\theta(\eta)$. For all graphs of the temperature dynamics, the values of $\mathrm{Rd}=1, K=\mathrm{Ec}=\mathrm{Sc}=0.2, \operatorname{Pr}=10$, and $M=\lambda=\mathrm{Nt}=\mathrm{Nb}=S=E=S_{0}=\delta_{1}=\delta_{2}=\delta_{3}=G_{t}=$ $G_{c}=0.1$. Figure 2 is prepared to visualize the fluctuation in the temperature distribution $\theta(\eta)$ in response to the variation in the magnetic effect $M$. The temperature of the fluid is increased as $M$ increases. This supports the general behaviour of the implementation of $M$. Resistance to the flow of the fluid is increased as $M$ increases due to which $\theta(\eta)$ is enhanced. The temperature distribution $\theta(\eta)$ is diminished as the stagnation parameter $S_{0}$ is enhanced. This effect is evident from Figures 3 and 4 demonstrated to view the effect of $\operatorname{Pr}$ on temperature distribution $\theta(\eta)$. These graphs indicate that upsurge in the Prandtl number Pr causes depreciation in the thermal profile. There is decline in the thermal conductivity of the fluid due to which $\theta(\eta)$ is reduced. Fluctuation due to electrical parameter $E$ in the temperature is divulged in Figure 5. An increment in $E$ results in an enhancement in thermal profile. As the Lorentz force is associated with the magnetic and electric field, it 
TABLE 1: Comparison of the presently computed values of $-\theta^{\prime}(0)$ and $-\phi^{\prime}(0)$.

\begin{tabular}{|c|c|c|c|c|c|c|c|}
\hline \multirow[b]{2}{*}{$\mathrm{Nt}$} & \multirow[b]{2}{*}{$\mathrm{Nb}$} & \multicolumn{3}{|c|}{$-\theta^{\prime}(0)$} & \multicolumn{3}{|c|}{$-\phi^{\prime}(0)$} \\
\hline & & [38] & [36] & Present & [38] & [36] & Present \\
\hline 0.1 & \multirow{5}{*}{0.1} & 0.9524 & 0.9524 & 0.952371 & 2.1294 & 2.1294 & 2.129356 \\
\hline 0.2 & & 0.6932 & 0.6932 & 0.693173 & 2.2740 & 2.2740 & 2.273956 \\
\hline 0.3 & & 0.5201 & 0.5201 & 0.520081 & 2.5286 & 2.5287 & 2.528542 \\
\hline 0.4 & & 0.4026 & 0.4026 & 0.402584 & 2.5752 & 2.5752 & 2.795041 \\
\hline 0.5 & & 0.3211 & 0.3211 & 0.321059 & 3.0351 & 3.0352 & 3.034979 \\
\hline \multirow{4}{*}{0.1} & 0.2 & 0.5056 & 0.5056 & 0.505580 & 2.3819 & 2.3819 & 2.381840 \\
\hline & 0.3 & 0.2522 & 0.2521 & 0.252156 & 2.4100 & 2.4100 & 2.409991 \\
\hline & 0.4 & 0.1194 & 0.1194 & 0.119406 & 2.3997 & 2.3997 & 2.399625 \\
\hline & 0.5 & 0.0543 & 0.0542 & 0.054254 & 2.3836 & 2.3836 & 2.383547 \\
\hline
\end{tabular}

Table 2: Numerical values of $-\theta^{\prime}(0)$ and $-\phi^{\prime}(0)$ with $\operatorname{Pr}=10$ and $\mathrm{Sc}=10$.

\begin{tabular}{|c|c|c|c|c|c|c|c|c|c|c|c|c|c|}
\hline K & $M$ & $S$ & $E$ & $\mathrm{Rd}$ & $\lambda$ & $S_{0}$ & $\delta_{1}$ & $\delta_{2}$ & $\delta_{3}$ & $G_{t}$ & $G_{c}$ & $-\theta^{\prime}(0)$ & $-\phi^{\prime}(0)$ \\
\hline 0.2 & 0.1 & 0.1 & 0.1 & 1 & 0.1 & 0.1 & 0.1 & 0.1 & 0.1 & 0.1 & 0.1 & 2.208651 & 2.024640 \\
\hline \multirow[t]{17}{*}{0.5} & & & & & & & & & & & & 2.232818 & 2.036448 \\
\hline & & & & & & & & & & & & 2.261914 & 2.050800 \\
\hline & 0.5 & & & & & & & & & & & 2.184588 & 2.084730 \\
\hline & 1 & & & & & & & & & & & 2.080667 & 2.150170 \\
\hline & 2 & & & & & & & & & & & 1.739265 & 2.272888 \\
\hline & & 0.2 & & & & & & & & & & 2.243757 & 2.041956 \\
\hline & & 0.3 & & & & & & & & & & 2.275876 & 2.058062 \\
\hline & & 0.4 & & & & & & & & & & 2.305543 & 2.073151 \\
\hline & & & 0.2 & & & & & & & & & 2.218326 & 2.024963 \\
\hline & & & 0.3 & & & & & & & & & 2.226200 & 2.025659 \\
\hline & & & 0.4 & & & & & & & & & 2.232293 & 2.026724 \\
\hline & & & & 2 & & & & & & & & 2.984161 & 2.071179 \\
\hline & & & & 3 & & & & & & & & 3.592600 & 2.106463 \\
\hline & & & & 4 & & & & & & & & 4.112293 & 2.133076 \\
\hline & & & & & 0.2 & & & & & & & 1.942647 & 2.096437 \\
\hline & & & & & 0.3 & & & & & & & 1.642765 & 2.176308 \\
\hline & & & & & 0.4 & & & & & & & 1.297555 & 2.266894 \\
\hline \multirow{18}{*}{1.0} & & & & & & 0.2 & & & & & & 2.642305 & 2.309297 \\
\hline & & & & & & 0.3 & & & & & & 3.086188 & 2.579879 \\
\hline & & & & & & 0.4 & & & & & & 3.535021 & 2.835314 \\
\hline & & & & & & & 0.2 & & & & & 2.150432 & 1.993731 \\
\hline & & & & & & & 0.3 & & & & & 2.101926 & 1.968131 \\
\hline & & & & & & & 0.4 & & & & & 2.060676 & 1.946477 \\
\hline & & & & & & & & 0.2 & & & & 2.040919 & 2.040302 \\
\hline & & & & & & & & 0.3 & & & & 1.893540 & 2.054700 \\
\hline & & & & & & & & 0.4 & & & & 1.763684 & 2.067856 \\
\hline & & & & & & & & & 0.2 & & & 2.289550 & 1.628650 \\
\hline & & & & & & & & & 0.3 & & & 2.345048 & 1.362008 \\
\hline & & & & & & & & & 0.4 & & & 2.385455 & 1.170300 \\
\hline & & & & & & & & & & 1 & & 2.274822 & 2.057306 \\
\hline & & & & & & & & & & 5 & & 2.488543 & 2.166622 \\
\hline & & & & & & & & & & 10 & & 2.670723 & 2.263403 \\
\hline & & & & & & & & & & & 1 & 2.251821 & 2.045980 \\
\hline & & & & & & & & & & & 5 & 2.405905 & 2.124113 \\
\hline & & & & & & & & & & & 10 & 2.549245 & 2.199092 \\
\hline
\end{tabular}

leads to an increment in the resistance causing the energy distribution to enhance. The influence of the thermal radiation parameter $\mathrm{Rd}$ on temperature distribution $\theta(\eta)$ is chalked out in Figure 6. These graphs reflect that an enhancement in Rd increases the energy profile. To visualize the behaviour of the thermophoresis parameter $\mathrm{Nt}$ on temperature, Figure 7 is sketched, which shows that there is an increment in $\theta(\eta)$ as $\mathrm{Nt}$ is hiked. Physically, in 


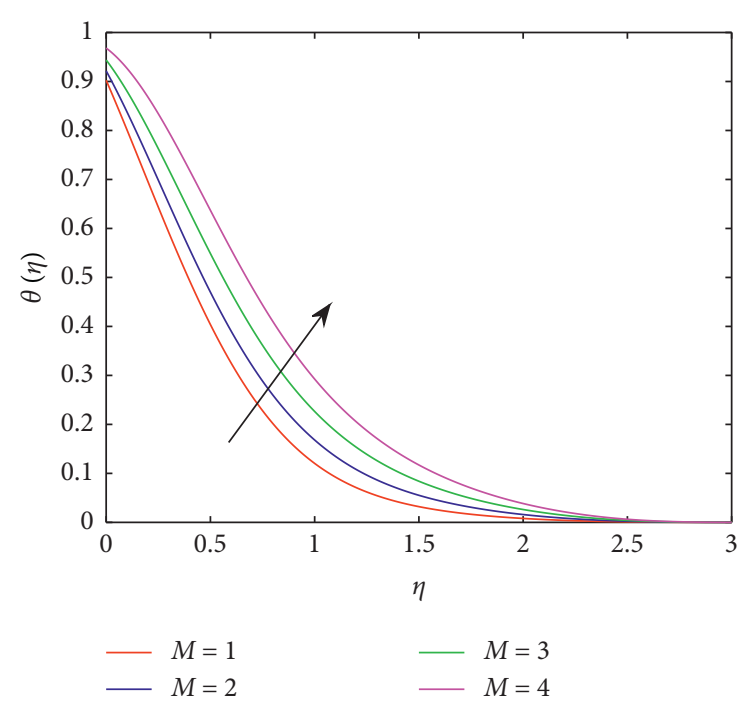

Figure 2: Variation due to $M$ in $\theta(\eta)$.

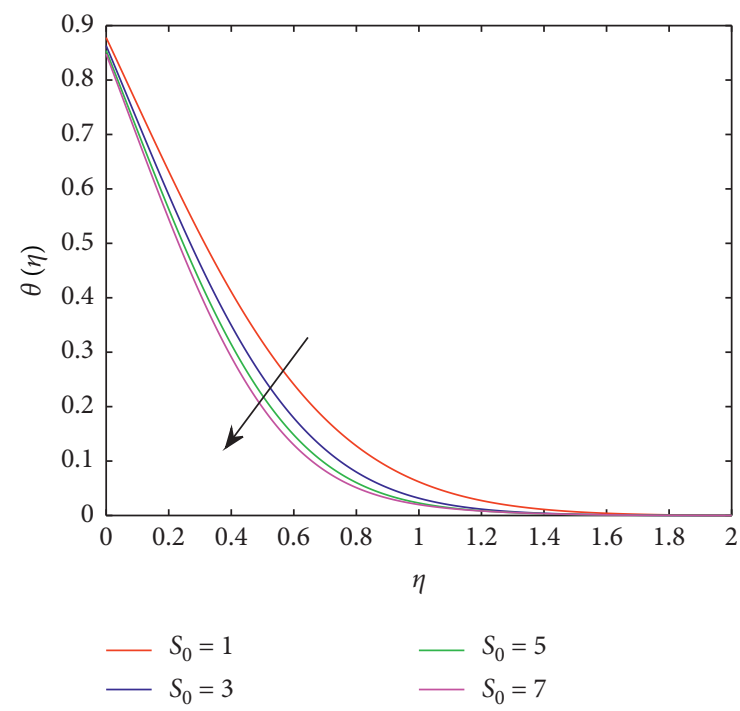

FIgURE 3: Variation due to $S_{0}$ in $\theta(\eta)$.

thermophoresis, the particles apply force on the other particles due to which particles from the hotter region move towards the colder region. Larger values of $\mathrm{Nt}$ denotes more application of the force on the other particles and as a result, more fluid moves from the higher temperature region to the colder region. Figure 8 shows that $\theta(\eta)$ is increased as the Brownian motion parameter $\mathrm{Nb}$ increases. Physically, the Brownian motion heats up the fluid and also aggravates the particles away from the fluid regime and therefore a decrement is seen in concentration profile. Figure 9 is illustrated to view the effect of heat generation coefficient $\lambda$ on $\theta(\eta)$, which shows that $\theta(\eta)$ is hiked for escalating values of $\lambda$. The viscous dissipation effect which is represented by the Eckert number Ec on energy field is analyzed in Figure 10. It is a number that represents the relation between the kinetic energy and the change in enthalpy. It is noticed that gradually boosting Ec leads to an increase in $\theta(\eta)$. Influence

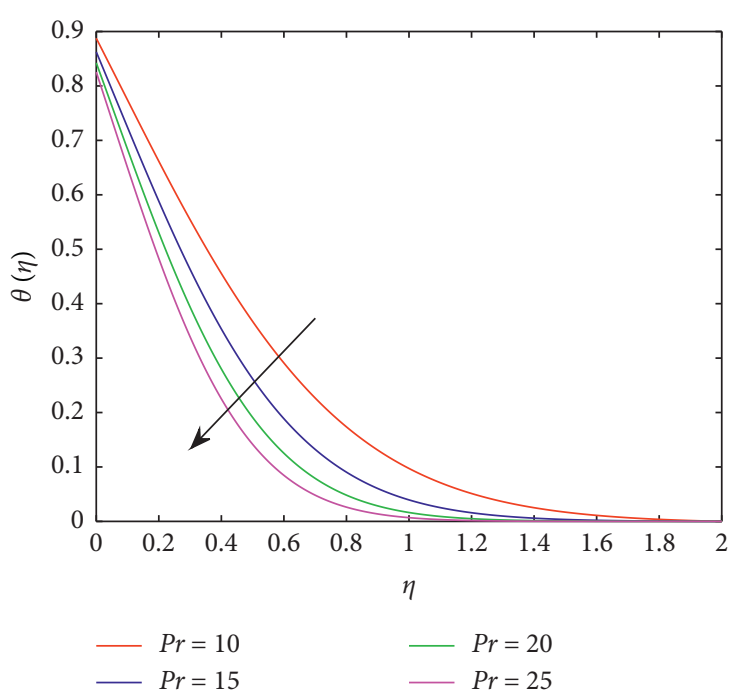

Figure 4: Variation due to $\operatorname{Pr}$ in $\theta(\eta)$.

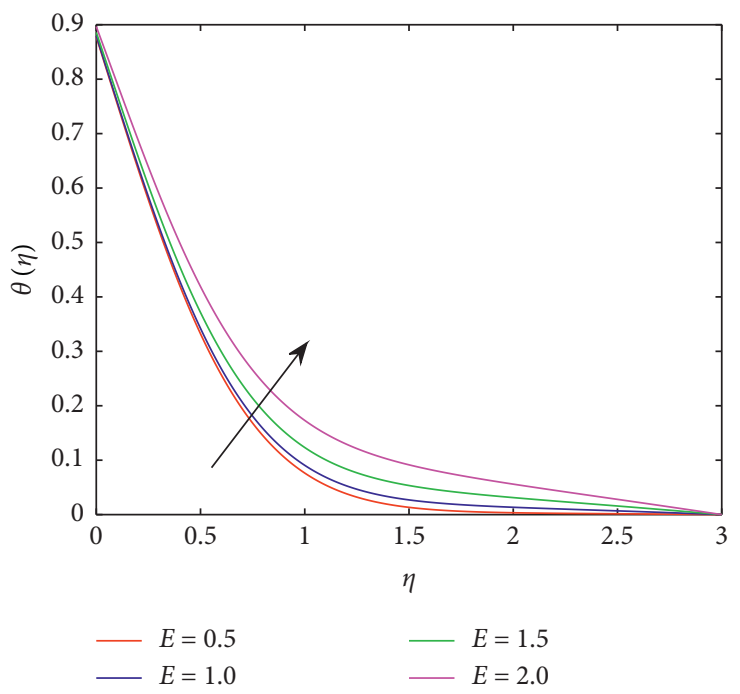

Figure 5: Variation due to $E$ in $\theta(\eta)$.

of the dimensionless slip parameter $S$ on $\theta(\eta)$ is presented in Figure 11, and it shows that an upsurge in $S$ encourages the energy distribution $\theta(\eta)$ to decline. The influence of the slip parameter $\delta_{2}$ which is associated with temperature on the temperature field is chalked out in Figure 12. The energy profile is found to be increasing as slip parameter $\delta_{2}$ goes up. The variation in the thermal profile due to the thermal free convection parameter $G_{t}$ is shown in Figure 13. The energy distribution declined as the thermal free convection parameter $G_{t}$ is hiked. Figure 14 depicts that the energy profile is decreases as $G_{c}$ is boosted.

Figures 15-23 have been outlined to study the fluctuations in the concentration field $\phi(\eta)$ due to variation in the governing parameters. For all the graphical presentations of $\phi(\eta)$, we have considered $\operatorname{Pr}=10, \mathrm{Nb}=0.3, \mathrm{Ec}=S c=K=$ 0.2 , and $M=\mathrm{Rd}=1, \lambda=\mathrm{Nt}=S=E=S_{0}=\delta_{1}=\delta_{2}=\delta_{3}=$ $G_{t}=G_{c}=0.1$. Figure 15 is given to study the impact of 


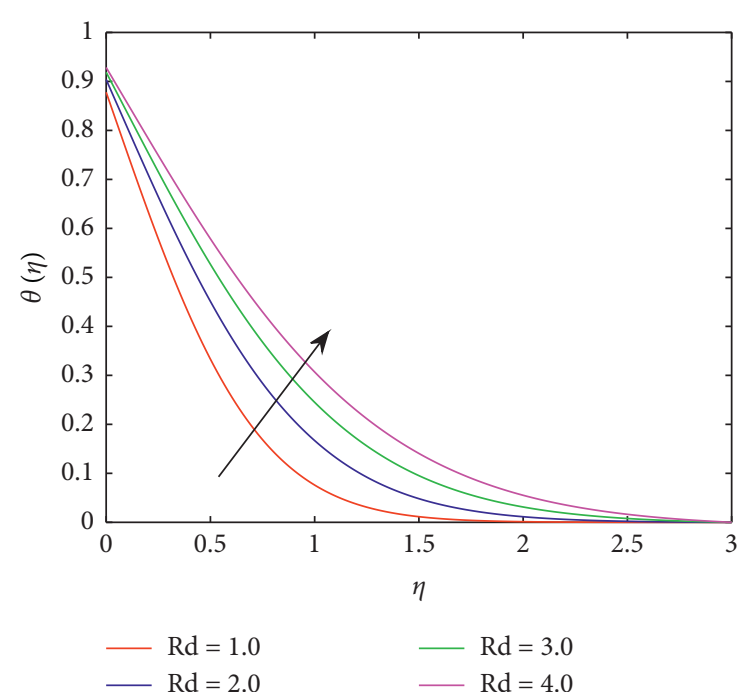

Figure 6: Variation due to $\mathrm{Rd}$ in $\theta(\eta)$.

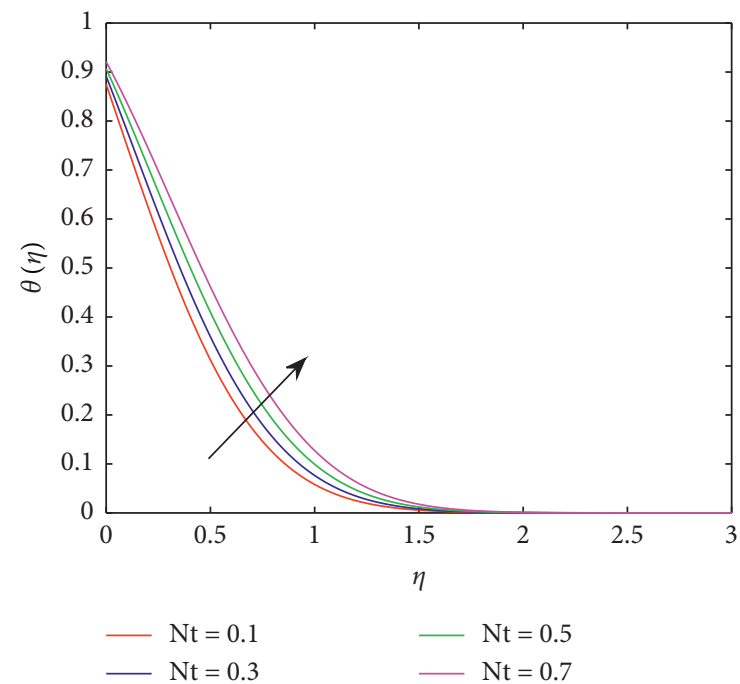

Figure 7: Variation due to $\mathrm{Nt}$ in $\theta(\eta)$.

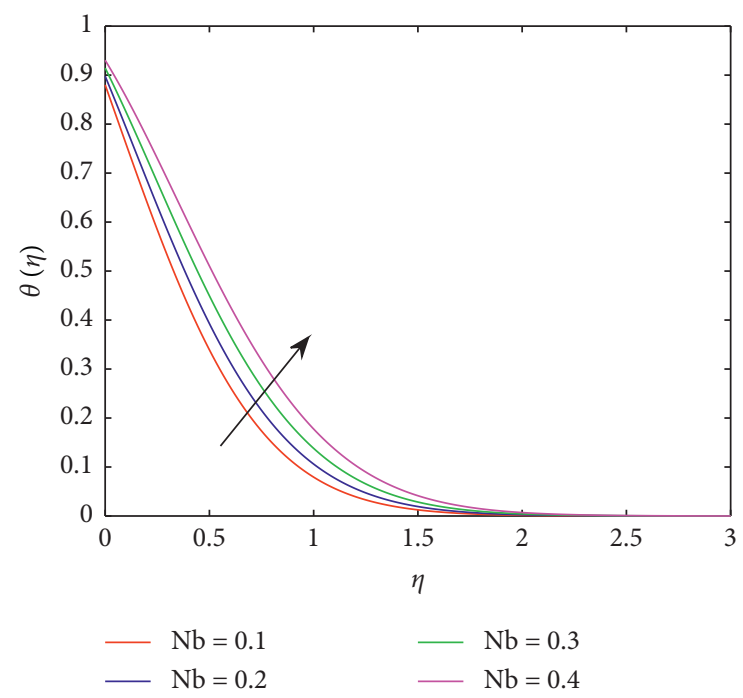

Figure 8: Variation due to $\mathrm{Nb}$ in $\theta(\eta)$.

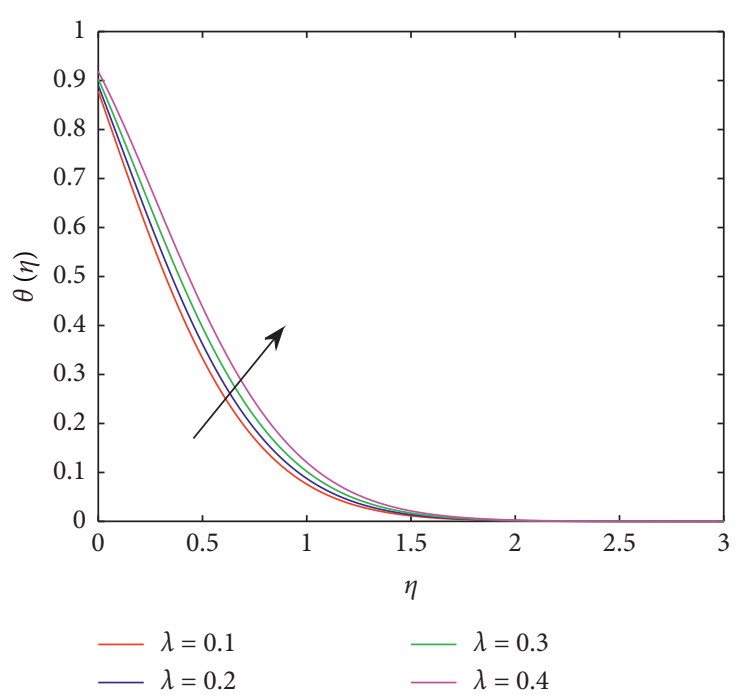

Figure 9: Variation due to $\lambda$ in $\theta(\eta)$.

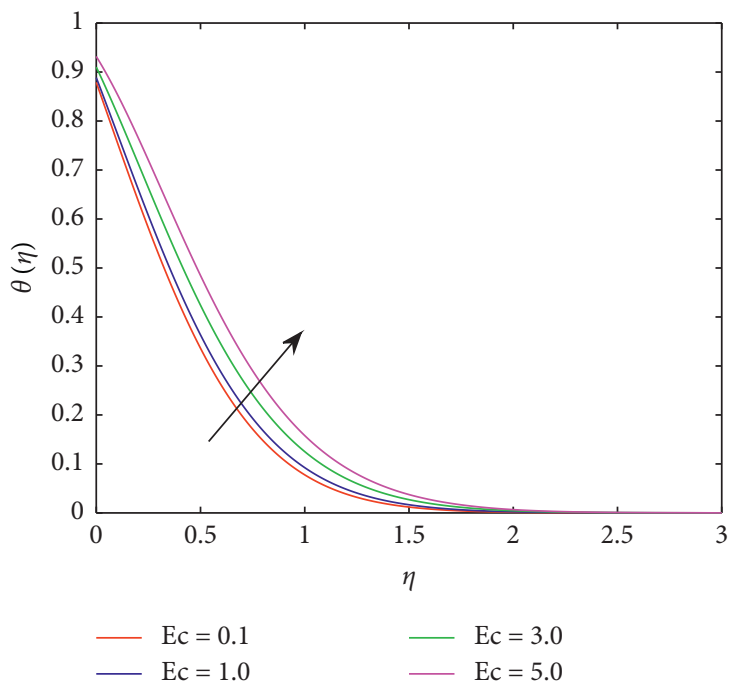

Figure 10: Variation due to Ec in $\theta(\eta)$.

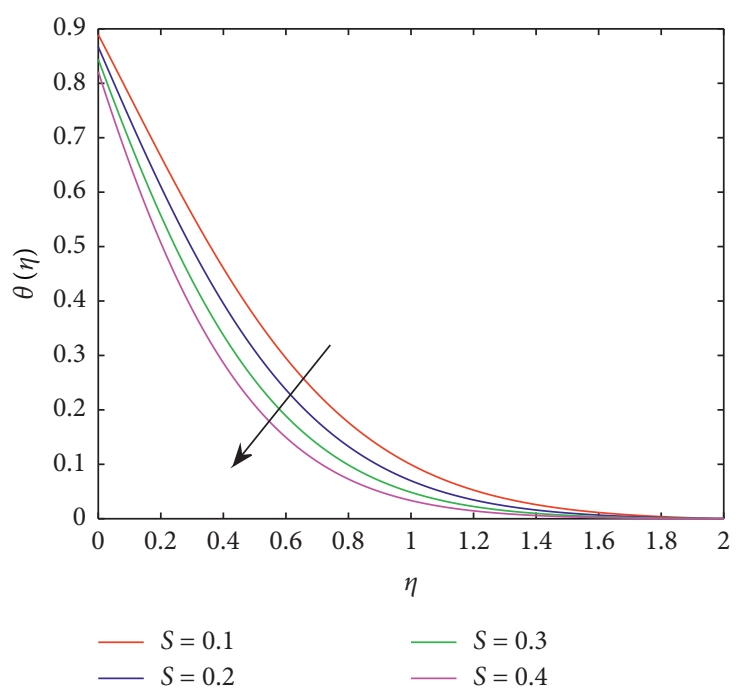

Figure 11: Variation due to $S$ in $\theta(\eta)$. 


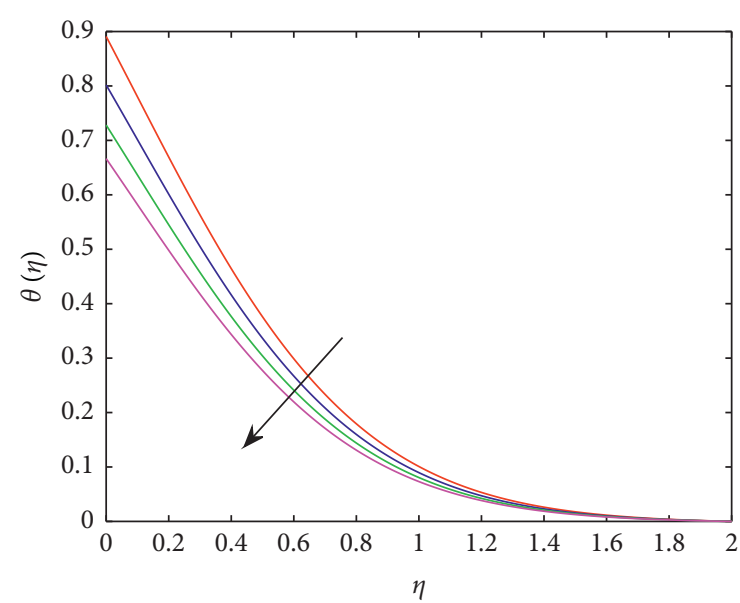

$$
\begin{aligned}
-\delta_{2}=0.1 & -\delta_{2}=0.3 \\
-\delta_{2}=0.2 & -\delta_{2}=0.4
\end{aligned}
$$

Figure 12: Variation due to $\delta_{2}$ in $\theta(\eta)$.

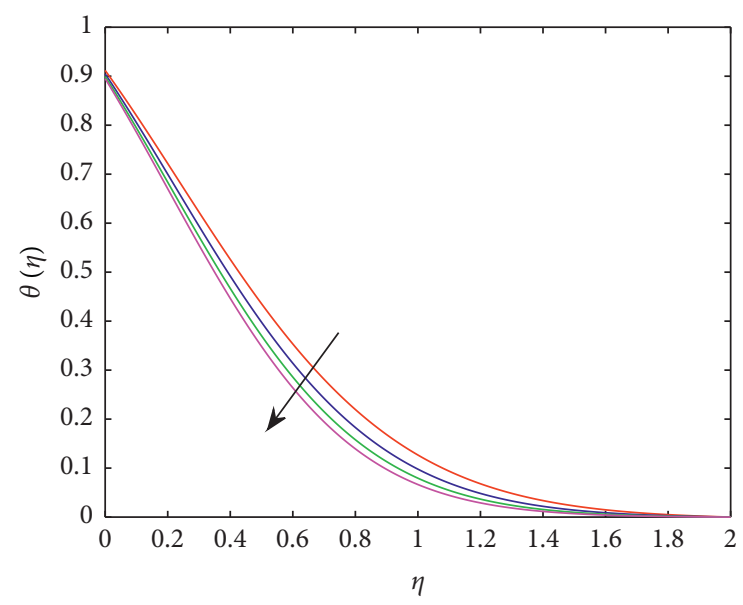
$-G_{t}=1$
$-G_{t}=3$
$-G_{t}=5$
$-G_{t}=7$

Figure 13: Variation due to $G_{t}$ in $\theta(\eta)$.

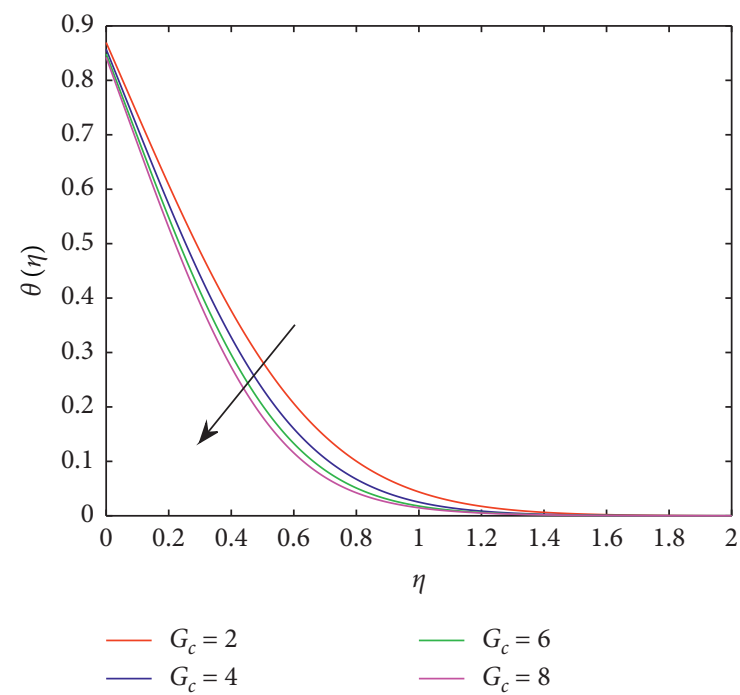

Figure 14: Variation due to $G_{c}$ in $\theta(\eta)$.

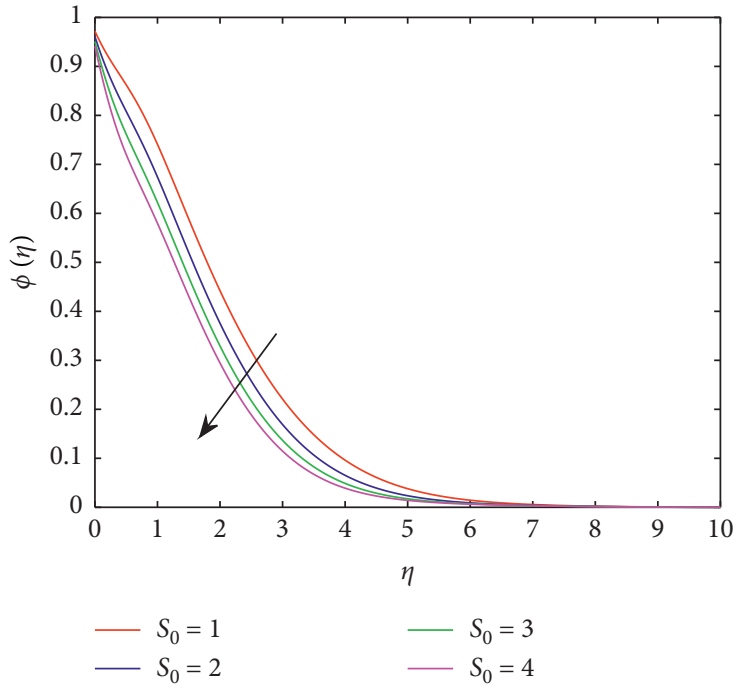

Figure 15: Variation due to $S_{0}$ in $\phi(\eta)$.

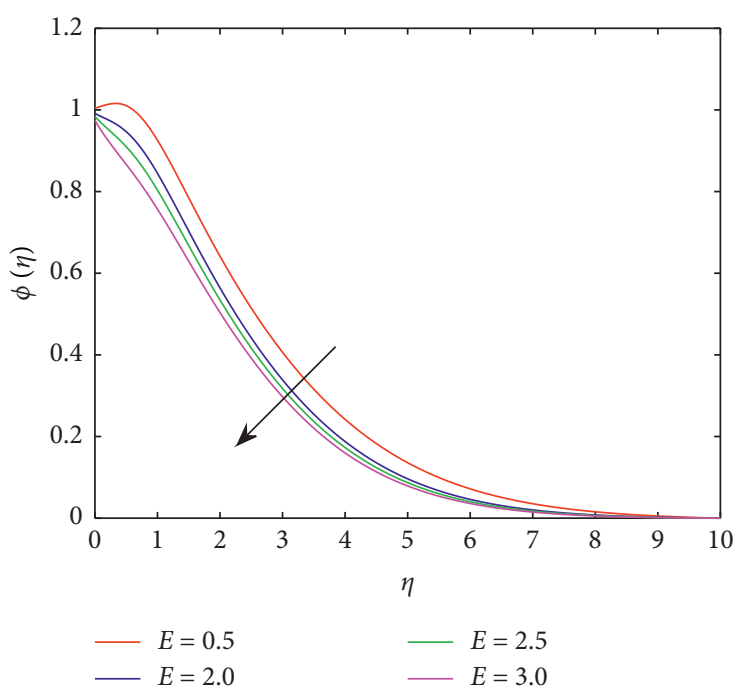

Figure 16: Variation due to $E$ in $\phi(\eta)$.

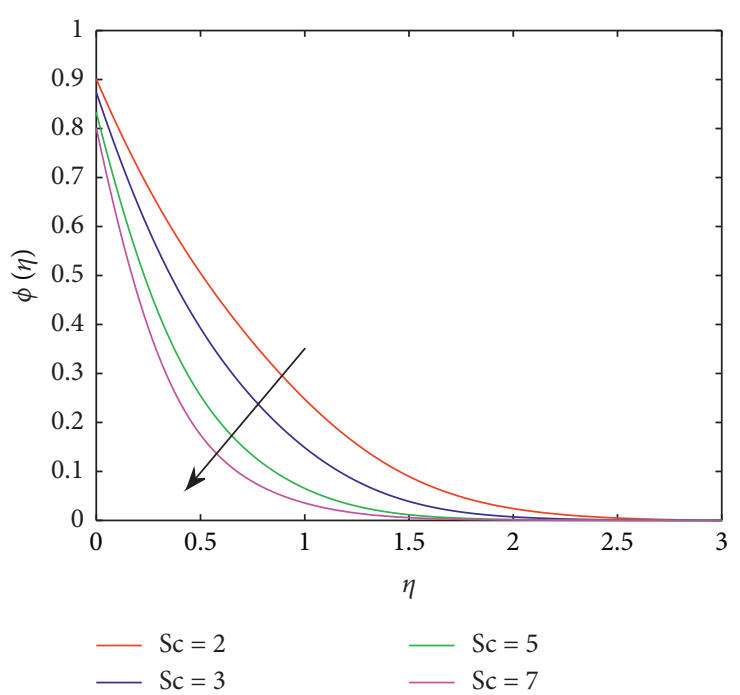

Figure 17: Variation due to Sc in $\phi(\eta)$. 

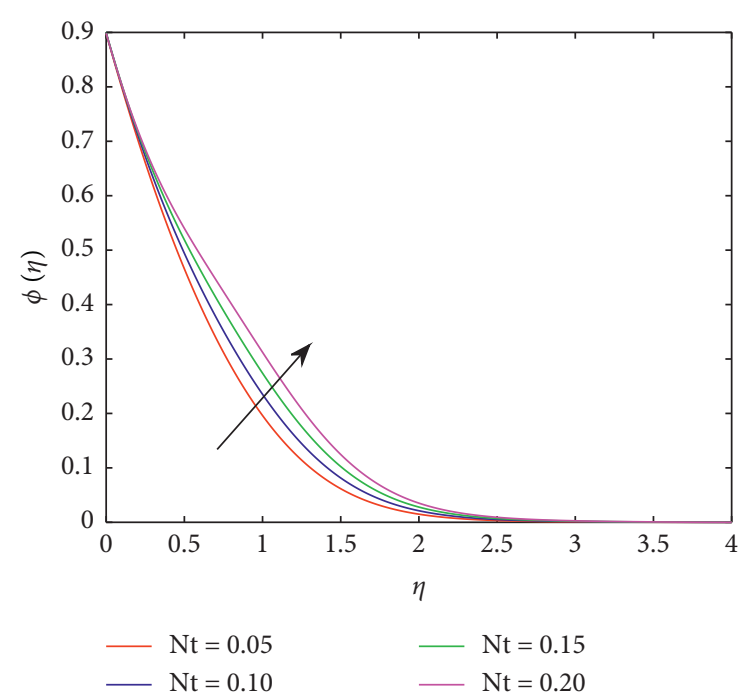

Figure 18: Variation due to $\mathrm{Nt}$ in $\phi(\eta)$.

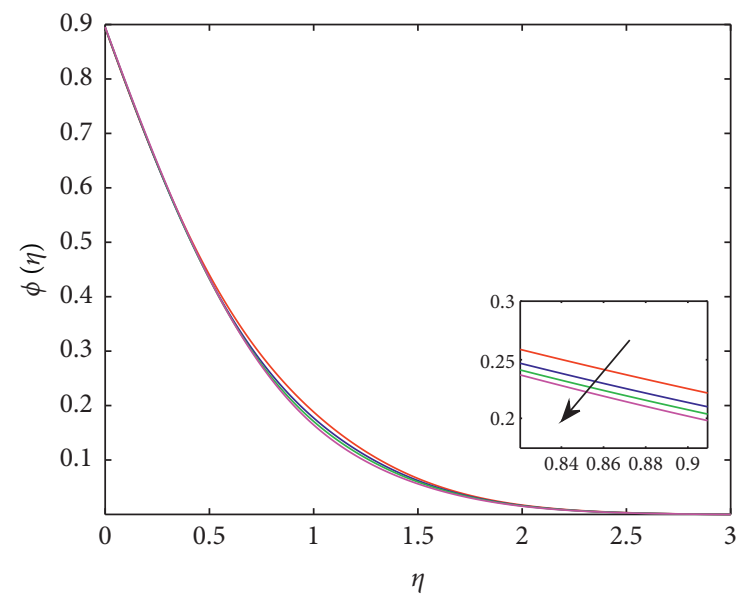

$-\mathrm{Nb}=1.0 \quad \mathrm{Nb}=2.0$

$-\mathrm{Nb}=1.5 \quad-\mathrm{Nb}=3.0$

Figure 19: Variation due to $\mathrm{Nb}$ in $\phi(\eta)$.

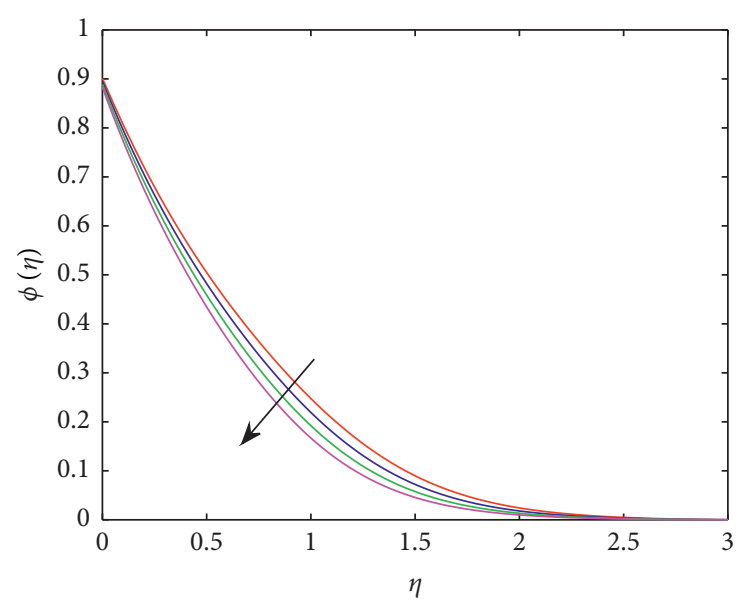

$$
\begin{aligned}
-S=0.1 & -S=0.3 \\
-S=0.2 & -S=0.4
\end{aligned}
$$

Figure 20: Variation due to $S$ in $\phi(\eta)$.

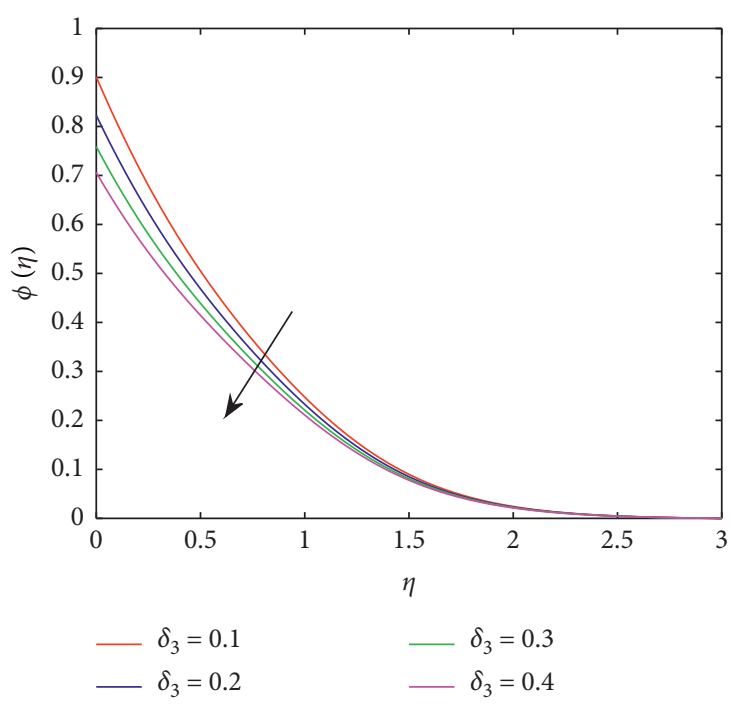

Figure 21: Variation due to $\delta_{3}$ in $\phi(\eta)$.

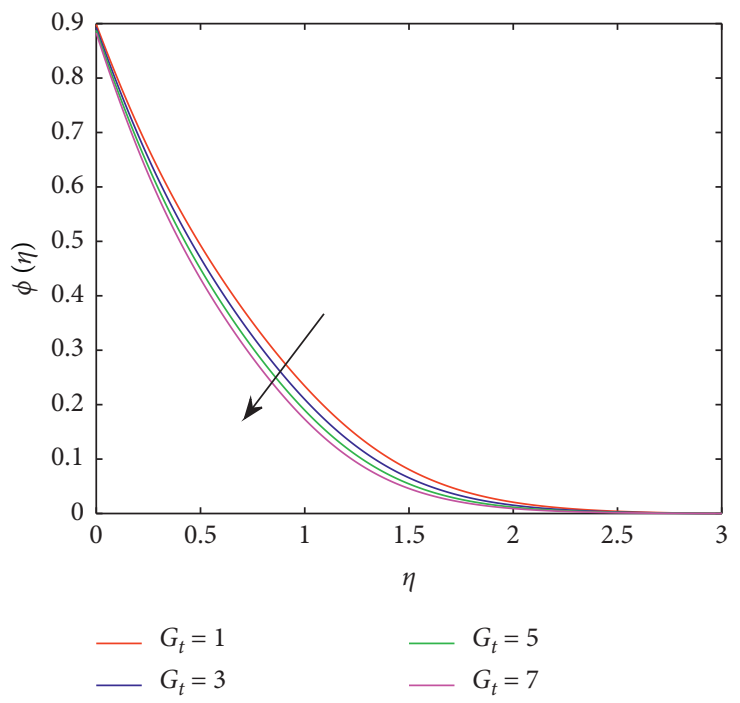

Figure 22: Variation due to $G_{t}$ in $\phi(\eta)$.

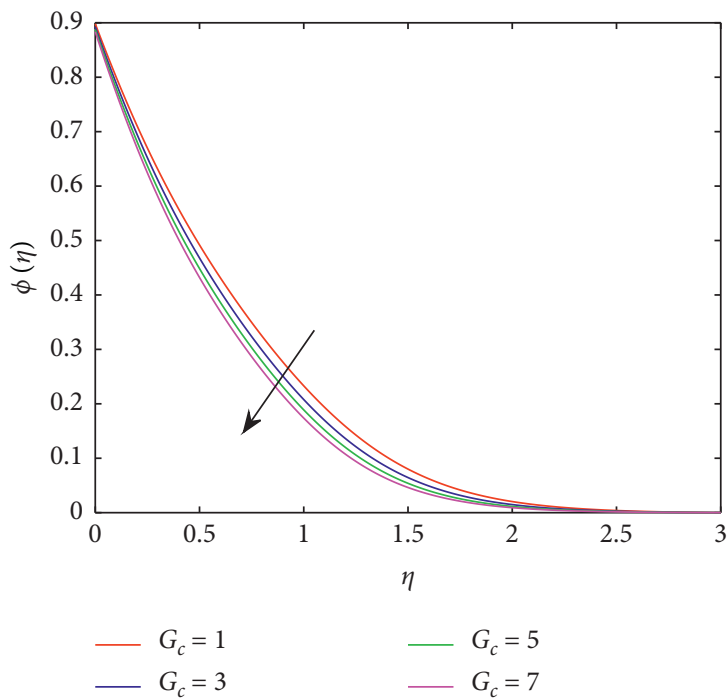

Figure 23: Variation due to $G_{c}$ in $\phi(\eta)$. 
stagnation parameter $S_{0}$ on $\phi(\eta)$. The concentration distribution $\phi(\eta)$ is diminished as the stagnation point parameter is enhanced. Figure 16 represents the graph of $\phi(\eta)$ for growing values of $E$. From these curves, it is clear that increasing electric parameter $E$ diminishes $\phi(\eta)$. Figure 17 presents the role of Schmidt number Sc in the variation of $\phi(\eta)$. The concentration field $\phi(\eta)$ is diminished as Sc is rapidly increased. The effect of Nt on dimensionless concentration field $\phi(\eta)$ is reported in Figure 18. These graphs present that concentration field is enhanced as Nt is gradually increased. Figure 19 is presented to view the fluctuation in dimensionless $\phi(\eta)$ caused by the increase in $\mathrm{Nb}$. An increase in dimensionless parameter $\mathrm{Nb}$ causes a reduction in $\phi(\eta)$. The impact of the variation of the dimensionless velocity slip parameter $S$ on the dimensionless $\phi(\eta)$ is shown in Figure 20. These curves indicate that with an increment in the velocity slip parameter $S$, the dimensionless $\phi(\eta)$ declined. Figure 21 depicts the graphs of the concentration profile for various values of the dimensionless diffusion slip parameter $\delta_{3}$. From these curves, it is noticed that an enhancement in the dimensionless diffusion slip parameter $\delta_{3}$ causes a decrease in $\phi(\eta)$. The fluctuation in the dimensionless concentration distribution due to the thermal free convection parameter $G_{t}$ is shown in Figure 22. The concentration field is reduced as thermal free convection parameter $G_{t}$ is increased. Figure 23 depicts that $\phi(\eta)$ is decreased as the mass free convection parameter $G_{c}$ is increased.

\section{Concluding Remarks}

In this study, two-dimensional free convection electrical magnetohydrodynamic micropolar nanofluid is analyzed. Some of the key observations are as follows:

(i) The energy field declined with an acclivity in the stagnation parameter $S_{0}$, slip parameter $S$, thermal free convection parameter $G_{t}$, and thermal slip parameter $\delta_{2}$

(ii) The Nusselt number is escalated for the increasing values of slip parameter $S$, electric parameter $E$, stagnation parameter $S_{0}$, and thermal radiation parameter Rd

(iii) The concentration field is diminished with an increase in stagnation parameter $S_{0}$, electric parameter $E$, diffusion thermal slip parameter $\delta_{3}$, and slip parameter $S$

(iv) The Sherwood number is increased as slip parameter $S$, electric parameter $E$, heat generation coefficient $\lambda$, stagnation parameter $S_{0}$, and mass free convection parameter $G_{c}$ are increased

\section{Nomenclature}

$B_{0}: \quad$ Applied magnetic field

$C: \quad$ Fluid concentration inside the boundary layer

$C_{\infty}$ : Fluid concentration outside the boundary layer

$C_{f}: \quad$ Skin friction coefficient

$C_{p}: \quad$ Specific heat
$C_{w}: \quad$ Concentration at wall surface

$D: \quad$ Coefficient of mass diffusion

$D_{B}: \quad$ Brownian diffusion coefficient

$D_{T}$ : Thermophoresis diffusion parameter

Ec: $\quad$ Eckert number

E: $\quad$ Electrical parameter

$f: \quad$ Reduced streamfunction

$h_{w}$ : Local surface heat flux transfer coefficient

$j: \quad$ Microinertia density

$j_{w}: \quad$ Local mass flux

$k_{f}$ : Thermal conductivity

$K$ : $\quad$ Material parameter

$M$ : $\quad$ Magnetic number

$\mathrm{Nu}_{x}: \quad$ Nusselt number

Nt: Thermophoresis parameter

$\mathrm{Nb}$ : Brownian motion parameter

$N$ : $\quad$ Angular velocity

Pr: $\quad$ Prandtl number

$q_{r}: \quad$ Radiative heat flux

$G_{t}: \quad$ Thermal free convection parameter

$q_{w}: \quad$ Heat transfer rate

Rd: Thermal radiation parameter

$\mathrm{Re}_{x}$ : Local Reynolds number

Sc: $\quad$ Schmidt number

$T: \quad$ Boundary layer temperature

$T_{w}: \quad$ Surface temperature

$T_{\infty}: \quad$ Ambient temperature

$t: \quad$ Time

$u$ : $\quad$ Velocity in $x$ direction

$u_{w}: \quad$ Characteristics velocity

$v: \quad$ Velocity in $y$ direction

$v_{w}: \quad$ Stretching rate

$S_{0}: \quad$ Stagnation parameter

S: $\quad$ Slip parameter

$v: \quad$ Kinematic viscosity

$\rho: \quad$ Fluid density

$\mu$ : $\quad$ Dynamic viscosity

$\sigma_{m}: \quad$ Electric charge density

$\theta: \quad$ Dimensionless temperature

$\phi: \quad$ Dimensionless concentration

$\gamma: \quad$ Spin gradient viscosity

$\eta: \quad$ Dimensionless boundary layer thickness

$\delta_{1}: \quad$ Dimensionless shear stress parameter

$\delta_{2}: \quad$ Thermal slip parameter

$\delta_{3}$ : $\quad$ Diffusion mass slip parameter

$\left(\rho C_{p}\right)_{p}$ : Heat capacity of the nanoparticles

$\left(\rho C_{p}\right)_{f}$ : Heat capacity of the fluid

$G_{c}: \quad$ Mass free convection parameter.

\section{Data Availability}

The experimental data used to support the findings of this study are included within this paper.

\section{Conflicts of Interest}

The authors declare that they have no conflicts of interest regarding the study. 


\section{Authors' Contributions}

All authors equally contributed to this work and read and approved the final manuscript.

\section{Acknowledgments}

The authors thank Dr. Muhammad Kashif Iqbal for his assistance in proofreading of the manuscript.

\section{References}

[1] H. Alfven, "Existence of electromagnetic-hydrodynamic waves," Nature, vol. 150, no. 3850, pp. 405-406, 1942.

[2] L. Zheng, J. Niu, X. Zhang, and Y. Gao, "MHD flow and heat transfer over a porous shrinking surface with velocity slip and temperature jump," International Journal of Biomathematics, vol. 56, no. 5-6, pp. 133-144, 2012.

[3] I. Ullah, K. Bhattacharyya, S. Shafie, and I. Khan, "Unsteady MHD mixed convection slip flow of Casson fluid over nonlinearly stretching sheet embedded in a porous medium with chemical reaction, thermal radiation, heat generation/ absorption and convective boundary conditions," PLoS One, vol. 11, no. 10, Article ID e0165348, 2016.

[4] A. Rahbari, M. Abbasi, I. Rahimipetroudi, B. Sundén, D. Domiri Ganji, and M. Gholami, "Heat transfer and MHD flow of non-Newtonian Maxwell fluid through a parallel plate channel: analytical and numerical solution," Mechanical Sciences, vol. 9, no. 1, pp. 61-70, 2018.

[5] S. K. Soid, A. Ishak, and I. Pop, "MHD flow and heat transfer over a radially stretching/shrinking disk," Chinese Journal of Physics, vol. 56, no. 1, pp. 58-66, 2018.

[6] S. M. Atif, S. Hussain, and M. Sagheer, "Effect of thermal radiation and variable thermal conductivity on magnetohydrodynamics squeezed flow of Carreau fluid over a sensor surface," Journal of Nanofluids, vol. 8, no. 4, pp. 806-816, 2019.

[7] K. V. Ramana, K. Gangadhar, T. Kannan, and A. J. Chamkha, "Cattaneo-Christov heat flux theory on transverse MHD oldroyd-B liquid over nonlinear stretched flow," Journal of Thermal Analysis and Calorimetry, vol. 43, 2021.

[8] M. Bibi, A. Zeeshan, M. Y. Malik, and K. U. Rehman, "Numerical investigation of the unsteady solid-particle flow of a tangent hyperbolic fluid with variable thermal conductivity and convective boundary," The European Physical Journal Plus, vol. 134, pp. 156-164, 2019.

[9] S. Shah, S. M. Atif, and A. Kamran, "Radiation and slip effects on MHD Maxwell nanofluid flow over an inclined surface with chemical reaction," Heat Transfer, vol. 50, no. 4, pp. 4062-4085, 2021.

[10] R. Jusoh, R. Nazar, and I. Pop, "Dual solutions of magnetohydrodynamic stagnation point flow and heat transfer of viscoelastic nanofluid over a permeable stretching/shrinking sheet with thermal radiation," Journal of Physics: Conference Series, vol. 890, 2017.

[11] H. U. Rasheed, S. Islam, S. Noor et al., "Impact of magnetohydrodynamics on stagnation point slip flow due to nonlinearly propagating sheet with nonuniform thermal reservoir," Mathematical Problems in Engineering, vol. 2020, Article ID 1794213, 2020.

[12] D. Pal and G. Mandal, "Magnetohydrodynamic stagnationpoint flow of Sisko nanofluid over a stretching sheet with suction," Propulsion and Power Research, vol. 9, no. 4, 2020.
[13] A. Abbasi, W. Farooq, and I. Riaz, "Stagnation point flow of Maxwell nanofluid containing gyrotactic micro-organism impinging obliquely on a convective surface," Heat Transfer, vol. 49, no. 5, pp. 2977-2999, 2020.

[14] L. A. Lund, Z. Omar, I. Khan, D. Baleanu, and K. S. Nisar, "Dual similarity solutions of MHD stagnation point flow of Casson fluid with effect of thermal radiation and viscous dissipation: stability analysis," Scientific Reports, vol. 10, 2020.

[15] S. E. Ghasemi and M. Hatami, "Solar radiation effects on MHD stagnation point flow and heat transfer of a nanofluid over a stretching sheet," Case Studies in Thermal Engineering, vol. 25, p. 100898, 2021.

[16] M. Irfan, W. A. Khan, M. Khan, and M. M. Gulzar, "Influence of arrhenius activation energy in chemically reactive radiative flow of 3D Carreau nanofluid with nonlinear mixed convection," Journal of Physics and Chemistry of Solids, vol. 125, pp. 141-152, 2019.

[17] S. M. Atif, S. Hussain, and M. Sagheer, "Effect of viscous dissipation and Joule heating on MHD radiative tangent hyperbolic nanofluid with convective and slip conditions," Journal of the Brazilian Society of Mechanical Sciences and Engineering, vol. 41, no. 4, pp. 189-206, 2019.

[18] S. M. Atif, S. Hussain, and M. Sagheer, "Heat and mass transfer analysis of time-dependent tangent hyperbolic nanofluid flow past a wedge," Physics Letters A, vol. 383, no. 11, pp. 1187-1198, 2019.

[19] M. Awais, K. U. Rehman, M. Y. Malik, A. Hussain, and T. Salahuddin, "A computational analysis subject to thermophysical aspects of Sisko fluid flow over a cylindrical surface," The European Physical Journal Plus, vol. 132, no. 9, pp. 392-407, 2017.

[20] A. Eringen, "Theory of micropolar fluids," Indiana University Mathematics Journal, vol. 16, no. 1, pp. 1-18, 1966.

[21] A. C. Eringen, "Theory of thermomicrofluids," Journal of Mathematical Analysis and Applications, vol. 38, no. 2, pp. 480-496, 1972.

[22] J. Sui, P. Zhao, Z. Cheng, L. Zheng, and X. Zhang, "A novel investigation of a micropolar fluid characterized by nonlinear constitutive diffusion model in boundary layer flow and heat transfer," Physics of Fluids, vol. 29, 2017.

[23] S. R. Mishra, I. Khan, Q. M. Al-Mdallal, and T. Asifa, "Free convective micropolar fluid flow and heat transfer over a shrinking sheet with heat source," Case Studies in Thermal Engineering, vol. 11, pp. 113-119, 2018.

[24] S. M. Atif, S. Hussain, and M. Sagheer, "Magnetohydrodynamic stratified bioconvective flow of micropolar nanofluid due to gyrotactic microorganisms," AIP Advances, vol. 9, no. 2, Article ID 025208, 2019.

[25] C. Zemedu and W. Ibrahim, "Nonlinear convection flow of micropolar nanofluid due to a rotating disk with multiple slip flow," Mathematical Problems in Engineering, vol. 2020, Article ID 4735650, 2020.

[26] S. U. S. Choi and J. A. Eastman, "Enhancing thermal conductivity of fluids with nanoparticles," ASME Fluids Engineering, vol. 231, pp. 99-105, 1995.

[27] S. O. Giwa, M. Sharifpur, and J. P. Meyer, "Experimental study of thermo-convection performance of hybrid nanofluids of $\mathrm{Al}_{2} \mathrm{O}_{3}-\mathrm{MWCNT} /$ water in a differentially heated square cavity," International Journal of Heat and Mass Transfer, vol. 148, 2020.

[28] W. A. Khan, F. Sultan, M. Ali, M. Shahzad, M. Khan, and M. Irfan, "Consequences of activation energy and binary chemical reaction for 3D flow of Cross-nanofluid with 
radiative heat transfer," Journal of the Brazilian Society of Mechanical Sciences and Engineering, vol. 41, no. 4, 2019.

[29] M. R. Eid, K. Mahny, A. Dar, and T. Muhammad, "Numerical study for Carreau nanofluid flow over a convectively heated nonlinear stretching surface with chemically reactive species," Physica A: Statistical Mechanics and its Applications, vol. 540, 2020.

[30] S. M. Atif, A. Kamran, and S. Shah, "MHD micropolar nanofluid with non Fourier and non Fick's law," International Communications in Heat and Mass Transfer, vol. 122, Article ID 105114, 2021.

[31] U. Ali, M. Y. Malik, A. A. Alderremy, S. Aly, and K. U. Rehman, "A generalized findings on thermal radiation and heat generation/absorption in nanofluid flow regime," Physica A: Statistical Mechanics and its Applications, vol. 553, Article ID 124026, 2020.

[32] S. M. Atif, S. Hussain, and M. Sagheer, "Numerical study of MHD micropolar Carreau nanofluid in the presence of induced magnetic field," AIP Advances, vol. 8, 2018.

[33] T. Muhammad, H. Waqas, S. A. Khan, R. Ellahi, and S. M. Sait, "Significance of nonlinear thermal radiation in 3D Eyring-Powell nanofluid flow with Arrhenius activation energy," Journal of Thermal Analysis and Calorimetry, vol. 143, 2020.

[34] S. A. Khan and M. A. Siddiqui, "Numerical studies on heat and fluid flow of nanofluid in a partially heated vertical annulus," Heat Transfer, vol. 49, no. 3, pp. 1458-1490, 2020.

[35] N. Manaa, A. Abidi, A. C. Saleel, and M. N. Borjini, "Threedimensional numerical analysis on performance enhancement of micropolar hybrid nanofluid in Comparison with simple nanofluid," Heat Transfer Engineering, pp. 1-21, 2020.

[36] K.-L. Hsiao, "Stagnation electrical MHD nanofluid mixed convection with slip boundary on a stretching sheet," Applied Thermal Engineering, vol. 98, pp. 850-861, 2016.

[37] M. Bilal, "Micropolar flow of EMHD nanofluid with nonlinear thermal radiation and slip effects," Alexandria Engineering Journal, vol. 59, no. 2, pp. 965-976, 2020.

[38] W. A. Khan and I. Pop, "Boundary-layer flow of a nanofluid past a stretching sheet," International Journal of Heat and Mass Transfer, vol. 53, no. 11-12, pp. 2477-2483, 2010. 